\title{
ENDONASAL LASER DACRYOCYSTORHINOSTOMY UNDER DIRECT VISION
}

\author{
M. K. TUTTON and N. P. O'DONNELL \\ Chester
}

\begin{abstract}
SUMMARY
We describe a method of endonasal laser dacryocystorhinostomy, using a neodynium-YAG laser, whose ease of performance should make it attractive to general ophthalmologists as an alternative to the routine external approach. A small series of 6 patients were investigated 6 months after surgery and a patent drainage system was revealed.
\end{abstract}

Dacryocystorhinostomy (DCR) is performed to connect the lacrimal sac directly to the nasal mucosa in order to bypass a lacrimal sac or nasolacrimal duct obstruction.

The approach to a DCR can be via an intranasal or external route, the former described originally by Caldwell in $1893,{ }^{1}$ the latter by Toti in $1904^{2}$ and later modified by Dupuy-Dutemps and Bourget in 1921. ${ }^{3}$ The intranasal route, however, lost its popularity in spite of its advantages such as the lack of cutaneous scar and little potential for damage to the lacrimal pump function. Part of the reason for this loss of popularity may have been the difficulty in obtaining adequate visualisation of the operation site during the intranasal approach with the technology available at the time. With the advent of fibreoptic technology to ensure acceptable visualisation the intranasal approach is now receiving more interest, especially in the otolaryngological literature. ${ }^{4-7}$

Recently endonasal laser DCRs have been described using high-energy argon, carbon dioxide or potassium titanyl phosphate and holmium lasers, with visualisation provided by the operating microscope or video endoscope. ${ }^{8,9}$ We describe the use of a continuous wave Sharplan 3000 neodymium-YAG (Nd-YAG) laser under direct vision in 6 patients followed up over 6 months and suggest that it is a technique that is easy to perform and does not require the purchase of expensive endoscopic equipment.

Correspondence to: $\mathrm{Mr}$ M. K. Tutton, Countess of Chester Hospital, Liverpool Road, Chester CH2 1DP, UK.

\section{PATIENTS AND METHODS}

Six patients, aged between 45 and 80 years (mean 65 years), with epiphora secondary to nasolacrimal duct obstruction, underwent endonasal laser DCR under direct vision. Four patients had had severe symptoms with discharge for 1-3.5 years (mean 2.25 years) and 2 patients had had moderate epiphora for 1.5 years and 10 years respectively. All patients underwent sac washout which revealed blockage distal to the lacrimal sac.

Following induction of the general anaesthetic $10 \%$ cocaine ointment was applied to the nasal mucosa in the region of the lacrimal fossa. A Cottle's nasal speculum was inserted into the nose to ensure adequate direct visualisation of the operation site. Canalicular patency was confirmed by probing of the upper and lower canaliculi through to the lacrimal sac.

A 20 gauge rigid fibreoptic light pipe was passed through the inferior punctum into the lacrimal sac and angled at $45^{\circ}$ to the nasal septum (Figs. 1,2). This produced a discernible light target when viewed through the nasal cavity.

A $400 \mathrm{~mm}$ plain fibreoptic fibre from a Sharplan $3000 \mathrm{Nd}-\mathrm{YAG}$ laser was passed into the nasal cavity to the site of the light source using an angled holder (Figs. 3, 4). Laser pulses of 3 seconds' duration and $30 \mathrm{~W}$ power were applied to the transilluminated area (total power used ranged from 390 to $1896 \mathrm{~J}$ ) until a rhinostomy was fashioned. The size of this rhinostomy was approximately $4 \mathrm{~mm}$. Suction was required to permit continuous visualisation and to evacuate smoke from the cauterised bone.

The upper lacrimal system was intubated with silicone O'Donoughue tubes, with their distal portion enclosed in a Wazke sleeve. They were left free within the nasal cavity in situ, for 2 to 6 months. No post-operative nasal packs or external dressings were required.

Eye (1995) 9, 485-487 C 1995 Royal College of Ophthalmologists 


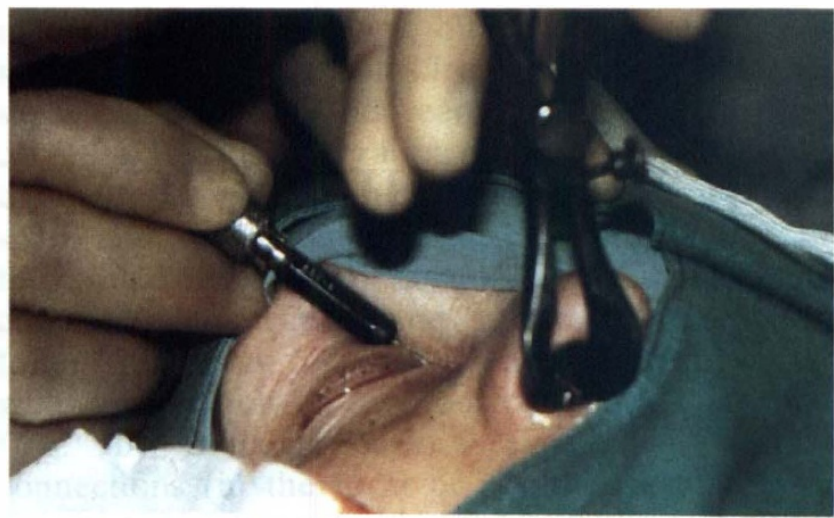

Fig. 1. A 20 gauge rigid light pipe is passed through the inferior punctum into the lacrymal sac.

\section{RESULTS}

Six months following surgery all the patients were reviewed. Each was questioned about any residual epiphora. All patients were pleased with the results of the operation. Two patients had residual epiphora, but only in windy conditions and this was not troublesome. A Jones Fluorescein Dye Test revealed patency of the lacrimal drainage system.

\section{DISCUSSION}

Endonasal laser DCR has a number of advantages over the conventional external approach to a DCR, namely lack of a cutaneous scar, little likelihood of interfering with the lacrimal pump mechanism, negligible intraoperative and post-operative bleeding, the potential of local anaesthetic day case procedures, and decreased risk of failure with a small-sized ostium. ${ }^{10}$

The preferred site for fistula formation is the postero-inferior region of the lacrimal fossa, where the apposition of lacrimal and nasal tissues is maximum. ${ }^{11}$ The use of a light pipe aids precise

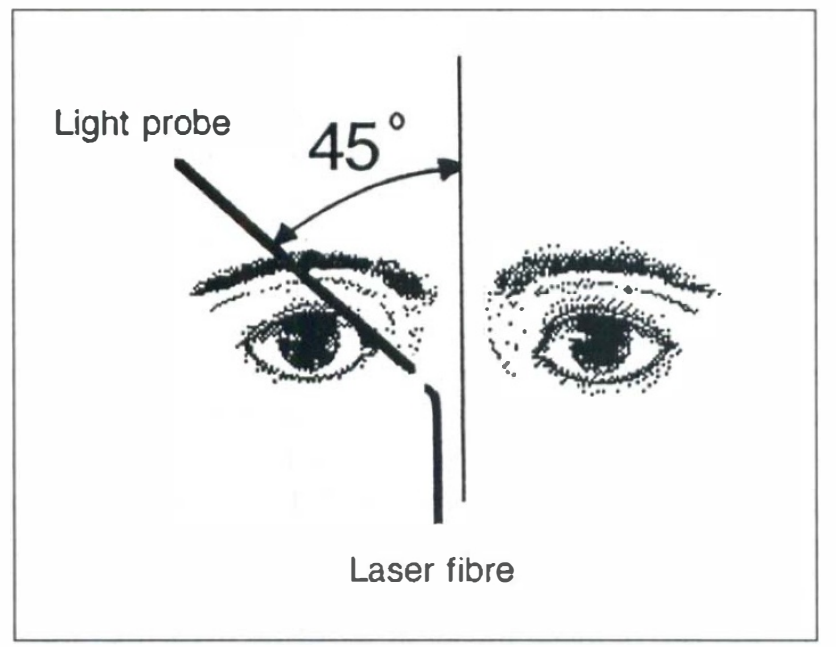

Fig. 2. The light pipe is angled $45^{\circ}$ from the vertical. This angulation ensures that the ostium is made at a lower level to make intubation easier.

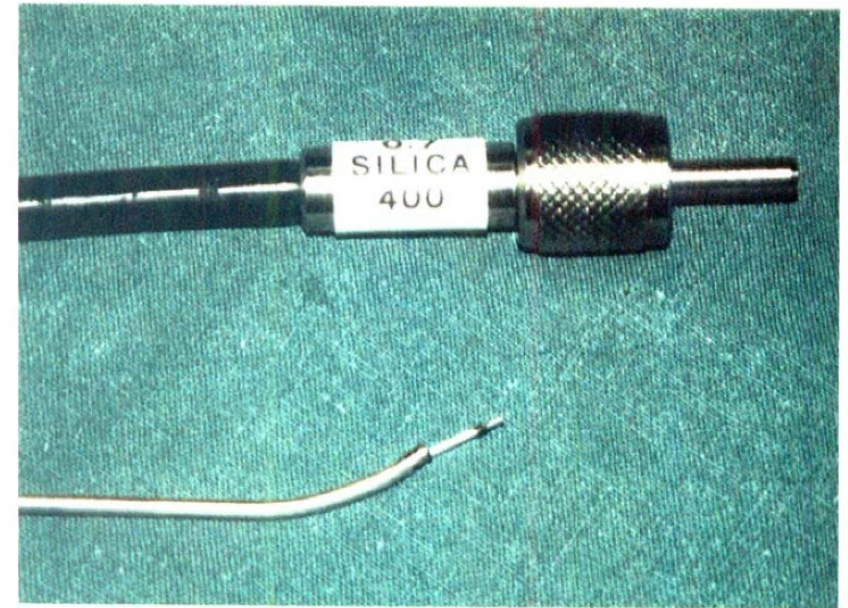

Fig. 3. A $400 \mathrm{~mm}$ plain optical fibre in the angled holder. Note the charring of the outer plastic sheath and the $3 \mathrm{~mm}$ of bare fibre at the tip.

identification of this area when viewed through the nose.

Among the commonest reasons for failure of external DCRs are primary closure, membranous occlusion of the ostium by synechiae between the surgical ostium and the adjacent nasal septum or middle turbinate, blockage of the ostium by the middle turbinate or deviated nasal septum or granuloma formation within the ostium. ${ }^{12}$ The ostium produced by the laser is smaller than that formed during conventional DCR, but it has been shown that despite the resection of large amounts of bone (up to $20 \mathrm{~mm}$ in diameter) the diameter of the ostium in these cases decreases to an average $1.80 \mathrm{~mm}^{10}$

A small ostium has a potential advantage of reducing the mobility of the silicone tubes, perhaps leading to less risk of extrusion of these before normal removal time. Bousch et al. ${ }^{12}$ have shown the importance of adequate tube retention for a successful outcome in these patients.

Contraindications to the endonasal approach

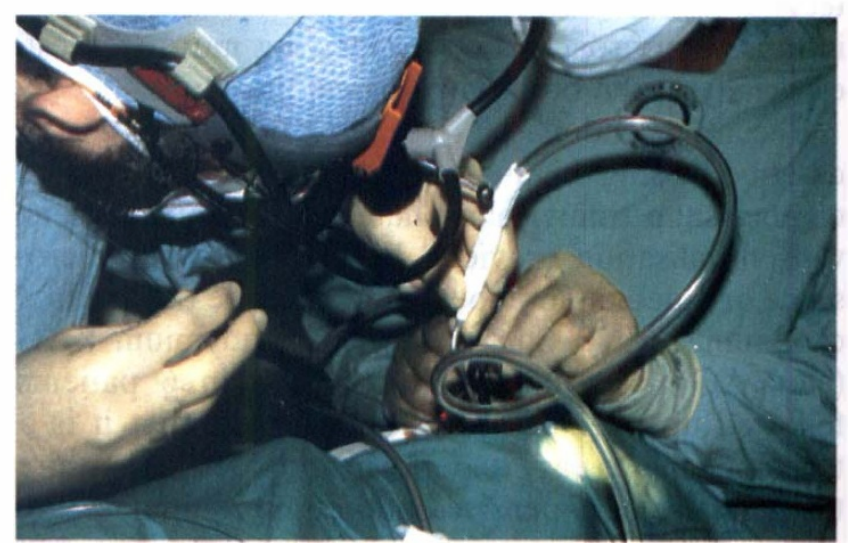

Fig. 4. The operating position. Note the surgeon's headlight, the angled suction tube, the Cottle's speculum in position, the angled holder and the laser fibre illuminated at its tip by the red helium-neon (HeNe) laser aiming beam. 
include suspected malignancy, previous trauma, and lacrimal sac diverticulum.

Visualisation in other described laser DCRs employs endoscopes or the operating microscope: we found adequate visualisation using a nasal speculum.

The ease of performing this procedure should encourage surgeons to follow a policy of early intervention in these patients, thus decreasing patients' chronic discomfort and increasing the likelihood of a successful outcome. The use of a laser employed by other surgical specialities would decrease the cost per case and negate the need to purchase expensive endoscopic equipment.

Although a large series of patients and a longer period of follow-up are required to assess the technique's effectiveness, we believe there is a place for this procedure in view of its simplicity and low cost.

Key words: Dacryocystorhinostomy, Endonasal laser, Lacrimal surgery.

\section{REFERENCES}

1. Caldwell GW. Two new operations for obstruction of the nasal duct with preservation of the canaliculi, and an incidental description of a new lachrymal probe. $\mathbf{N}$ Y Med J 1893;57:581.
2. Toti A. Nuovo metodo conservatoire di cura radicale delle suppurazioni croniche del sacco lacrimale (dacriocistorinostomia). Clin Mod Pisa 1904;10:385-7.

3. Dupuy-Dutemps L, Bourguet M. Procede plastique de dacryo-cystorhinostomie et ses resultats. Ann Ocul 1921;158:241-61.

4. Jokinen K, Karja J. Endonasal dacryocystorhinostomy. Arch Otolaryngol Head Neck Surg 1974;100:41-4.

5. Steadman GM. Transnasal dacryocystorhinostomy. Otolaryngol Clin North Am 1985;18:107-11.

6. Rice DH. Endoscopic intranasal dacryocystorhinostomy: a cadaver study. Am J Rhinol 1988;2:127.

7. Stammberger H. Endoscopic endonasal surgery: concepts in treatment of recurring rhinosinusitis. I. Anatomic and pathophysiologic considerations. Otolaryngol Head Neck Surg 1986;94:143.

8. Massero M, Gonnering RS, Harris GJ. Endonasal laser dacryocystorhinostomy: a new approach to nasolacrimal duct obstruction. Arch Ophthalmol 1990;108:1172.

9. Woog JJ, Metson R, Puliafito CA. Holmium:YAG endonasal laser dacryocystorhinostomy. Am J Ophthalmol 1993;116:1-10.

10. Bartley GB. The pros and cons of laser dacryocystorhinostomy. Am J Ophthalmol 1992;117:103-6.

11. Gonnering RS, Lyon DB, Fisher JC. Endoscopic laser assisted lacrimal surgery. Am J Ophthalmol 1991; 111:152.

12. Boush GA, Lemke BN, Dortzbach RK. Results of endonasal laser-assisted dacryocystorhinostomy. Ophthalmology 1994;101:955-9. 